BLTALL (ENGLISH IANGUAGE 'TEACHING, APPLIED IINGUIS'TICS

Available online at https://jurnal.iainponorogo.ac.id/index.php/eltall

\title{
BLENDED LEARNING ENVIRONMENT: PROMOTING LEARNERS' SELF-EFFICACY
}

\author{
Desi Puspitasari \\ Institut Agama Islam Negeri Ponorogo \\ desipus@iainponorogo.ac.id
}

\begin{abstract}
In recent years, blended learning has been utilizing in a variety of contexts. It emerges as one of the most popular pedagogical approaches which integrate faceto-face classes with the virtual learning environment. It offers learners considerable resources and materials. Many researchers have reported on it since it thrived. It offers learners flexibility. It also gives the learners choices about when and where they learn and participate in online learning. Therefore, it is used for teaching and training worldwide since many researchers found it an effective way to be used in the teaching-learning process. It is believed to enhance learners' understanding of learning a foreign language. Some researchers also found that blended learning affects learners' self-efficacy stronger than the other instructional modes. This study employed qualitative research. It was used to determine how blended learning was applied in a class to boost learners' self-efficacy. In conclusion, the developments of technology recently encourage educators to apply a blended learning environment in the classroom. One of the important things is how it should be implemented to help the learners develop their self-efficacy and achieve their academic goals.
\end{abstract}

Keywords: blended learning, learning environment, self-efficacy

\section{INTRODUCTION}

Nowadays, the world has come to a disruptive era. It is also known as the intelligent industry. It is considered the fourth industrial revolution, coined by Professor Schwab (Effoduh, 2016). It requires digital transformation. The change is based on the adoption of technologies. It deals with the innovation which will be developed day by day.

Education does not merely remain to set up the same classrooms. It is time for the teachers and learners to access the technology to explore new and innovative teaching and learning things. Higher education is an obscure, rationalistic, and energizing open door that can change society to improve things (Shahroom \& Hussin, 2018, p. 316). Thus, teachers and learners should equip themselves with 
technology to face the intelligent era. They have to be ready for that as it gives implications on the changes and shifts on both sources and methods in learning English.

Combining face-to-face and online learning is becoming a new method of teaching and learning. It is called blended learning. It is an educational program in which learners learn, in part, through online learning, with some control over time, place, path, and pace (Maxwell, 2016). Hence, learners can benefit from it that space and distance do not matter anymore.

The face-to-face classroom exists in the present. It gives an overview of where the class is and how the progressing is. Both teachers and learners interact in the real classes. The teachers can respond immediately to any misconceptions the learners have. They give correction of the students' understanding directly. It is also helpful to live up the curriculum and focus on the entire group's attention. It enables the teachers to observe the learners' works and collaborate and teach them in a collaborative manner that develops interpersonal skills (Fahlvik, 2014).

Interpersonal skills are closely linked to self-efficacy. Rubin, Martin, Bruning, \& Powers (1993) found that self-efficacy mediated the impact of experience and situational difficulties on interpersonal communication outcomes. Self-efficacy is a person's belief in their capability to perform a particular task successfully (Bandura, 1977). It is distinct from the concept of self-confidence. It is a general personality trait that relates to how people act in most situations.

Self-efficacy, on the other hand, concerns particular tasks. Thus, for specific duties, learners can have high self-efficacy for some tasks and low self-efficacy for others. Moreover, Bandura (1977) also claimed that self-efficacy is built more readily developed than self-confidence or self-esteem. It is a better indicator of how the individual can successfully perform the tasks effectively than their level of self-confidence or self-esteem.

By applying blended learning, the classroom activities might change to warrant a rethink of the type of room used as the example is the teaching-learning process that needs a big class to deliver for about two up to three hours. It might be exchanged for a flipped-classroom approach by engaging interactive materials to access it online. It can be followed by small group work, seminars, discussion, or working on real-life case studies. It is expected that the learners will have better performance on how to overcome the tasks. Therefore, this study needs to be conducted to determine how a blended learning environment empowers learners' self-efficacy. 


\section{METHOD}

This study employed a qualitative approach. It was defined as any research that produced findings utilizing statistical procedures or other means of quantification (Strauss \& Corbin, 1990, p. 17). This approach required the researchers to seek instead of illumination, understanding, and extrapolation to similar situations.

Qualitative research focuses on understanding the humanistic approach to a research query. It is used to understand people's beliefs, experiences, attitudes, behaviors, and interactions. It was recognized as an approach in psychological studies to evaluate human behavior. Since then, it is used in other research fields as well. One of the fields is education. Therefore, this study retains a qualitative research design since it is used to describe how a blended learning environment increases the learners' self-efficacy.

This study was a theoretical research paper. It is carried out in the interpretive paradigm. It explored the beliefs related to blended learning and self-efficacy. It defined blended learning and then played out the implications of the phenomena.

\section{RESULTS AND DISCUSSION Blended Learning}

Blended learning provides educators and learners with more opportunities for the teachers and learners to improve their skills. It happens when the learners study in a supervised brick-and-mortar location away from home, at least partially (Maxwell, 2016). It implies that with teachers or guides, the learners attend a physical school. In other words, the online and face-to-face elements work together to provide an integrated course while learners are learning in a mixed-way. Olah (2019) also notes that a blended learning environment is a structured education program in which a student learns at least partly through online learning, with some aspects of student control over time, venue, direction, or speed, and at least partly in a brick-and-mortar supervised location away from home.

Blended learning has some benefits for both teachers and learners. Tomlinson \& Whittaker (2013) states there are some crucial things why blended learning is needed. One of them is responding more appropriately to learning styles. Learners have the chance to work in a way that suits them without disrupting others by using blended learning. It provides a versatility that allows students to study whenever they want, anywhere, and at their own pace. It also makes teachers adapt more effectively to the various learning styles of learners. 
The next benefit is that it offers to learn a more in-depth approach. Without feeling insufficient, learners can watch any video or listen to the audio as many times as possible. It helps learners to choose their direction based on their needs and desires through the most suitable means. They can go back to refresh their knowledge or, according to their situation, move on. It thus enhances learners' enthusiasm by inspiring them through the help inherent in the blended learning process.

Blended learning gives the learners more individual focus as well. It enables educators to give the attention they deserve to all learners. It is accomplished by designing a course that will take the learners' needs more closely into account. Learners are encouraged to extend their understanding and go beyond what is needed in the course. According to their speed, they will review and consolidate anything online that has been presented in the classroom.

The blended learning methodology offers the teachers a visual description of the success of individual learners. It offers the opportunity for learners to provide feedback. It enhances their performance and the ability to update and change course content to respond to learners' needs whenever necessary (Cotfas, Cotfas, \& Kaplanis, 2013).

It is said that blended learning maximizes classroom social interaction. The learning environment provides a shared space where it is possible to serve communication as a social activity. Thus, the instructor has more time for the learners to construct engaging learning experiences. Teachers can take a back seat and let them interact with their peers in real-time. The teachers also listen intently to the learners. It enables them to respond adequately at a particular moment in time to the needs of the learners.

In order to improve motivation and interpersonal capacity, blended learning is crucial. Technology provides real-time methods in a blended approach by instantly giving input. It also offers several learning resources, various types of activities, activities that can be accessed at any time, whenever appropriate. It needs the supervision of the learners in their learning processes. It pushes them, thus, to be independent learners.

\section{The Role of Blended Learning Environment}

A mixed learning environment helps the learners to experience something on their own. It allows learners to learn about autonomy. It represents what they understand and what they have experienced. They expand on it, then. It allows them to improve their skills further. They will be more positive and independent learners as the students are getting proficient. Since both have fulfilled their duties, 
the relationship between teachers and learners tends to fade away. The trainer respects the interests of the learners and assumes responsibility for their learning. As a result, it allows both teachers and learners to perform their ultimate positions when their components are effectively integrated.

Some scientists believe that blended learning is fruitful. It makes the empowerment of learners simpler than face-to-face or entirely online courses (Owston, 2018). Moreover, empowerment is characterized by Thomas \& Velthouse (1990) as increased intrinsic motivation. They propose four cognitions (task assessments). They are the cornerstone of empowerment, sense of effect, skill, significance, and choice.

Shea \& Bidjerano (2010) argue that there is a positive relationship between the structure of the CoI (Community of Inquiry) and elements of a nascent theoretical construct called' presence of learning.' They said that learning represents some elements, such as self-efficacy and the other cognitive, behavioral, and motivational constructs of online learners' self-regulation.

Owston (2018) also said that blended learning offers preference and versatility in learning for learners. When and where they can participate in the online course, the learners can choose. It also shows that in blended learning, selfefficacy is greater than the other modes of instruction. Also, learners tend to do higher in blended courses than in completely online or face-to-face courses. It has a strong sense of succeeding, thus.

Nguyen (2010) notes that both traditional face-to-face and online interaction are merged in a blended learning environment. It is an excellent option for higher education that many teachers follow in $100 \%$ of online teaching environments. It is said that blended courses, including comprehensive online courses, give learners the flexibility of online access to both lecture/course materials and discussions in the asynchronous classroom. However, the essential aspect of a blended learning environment is to use conventional face-to-face sessions to promote and stimulate an online social culture that promotes the acquisition of information through interpersonal and community discussion and disclosure.

\section{Self-efficacy}

A study conducted by Lynch \& Dembo (2004) found that in a blended educational setting, distance education and self-regulation literature identify learner self-regulation skills predictive of academic performance. Five selfregulatory attributes were judged to be academic success predictive. They are intrinsic target focus, learning and success self-efficacy, control of time and research setting, help-seeking, and self-efficacy on the internet. They said that as a 
controlling factor, verbal capacity was used. Besides, the performance was operationalized as grades of the final course.

Self-efficacy is one of the critical aspects of self-regulation. Self-efficacy beliefs are individuals' beliefs regarding their ability to achieve desirable results through their actions (Maddux, 2016). Thus, the self-efficacy assessment should be structured to achieve the various characteristics of the learners. The attitude of concern and the circumstances in which it arises should also be investigated. It is more likely that people who have a greater motivation to accomplish the tasks well would set more explicit and more challenging targets. It is correlated with the accomplishment of goals, which strengthens assumptions about self-efficacy.

The contribution of learners' ever-evolving views of their academic abilities has been discussed through self-efficacy theory research. Also, it affects their confidence that they can complete particular academic tasks, forecasts academic performance, and perceive experiences of success and failure. Maddux (2016) also said that students with higher academic self-efficacy levels show higher academic goal-setting, appreciate academic achievement more, spend twice as much time studying, receive higher grades, and record higher focus and control when doing homework, compared to students with lower academic self-efficacy.

\section{The Implementation of Blended Learning in Developing Learners' Self- efficacy}

Blended learning provides discretion and versatility for learners when and where they can engage in their course's online section. As satisfaction appears to be higher than in entirely online or face-to-face classes, this approach also gives them opportunities to select their preferred learning form. In blended classes, selfefficacy is usually more significant than the other two instruction modes to explore their abilities based on their interests. Thus, in entirely online or face-to-face classes, they prefer to do better than their peers because they have a greater sense of achievement.

The cognitive model of empowerment is dealt with through blended learning. It is an intrinsic motivation based on a sense of effect, competence, importance, and preference. It empowers the self-efficacy of the learners by following the interpretive viewpoint. Since high self-efficacy leads individuals to work hard and endure in the face of setbacks, it plays a vital role.

Blended learning demands the learners to be independent learners. They should take responsibility for their learning. Frankly, the teachers need to revise their syllabus. It is revised based on the constructivist pedagogy, which encourages the learners' self-efficacy. Furthermore, implementing blended learning in the teaching process is not as easy as falling off a log. It needs supports from the other elements, such as policymakers. They need to collaborate in advancing the new 
paradigm on how the learners study. The improvement is also needed for the teachers' teaching strategies to heighten the learners' self-efficacy.

\section{CONCLUSION}

The disruptive era which compromises the development of technology suggests a new paradigm in the teaching-learning process. It is called blended learning. Thus, teachers apply it to their classrooms as the current trends in teaching. They implement it to encourage the learners to think about the materials in numerous ways. They do not only sit in the class, but they can also evolve their online learning capabilities.

Self-efficacy is the confidence of learners in their ability to accomplish their objectives. Using the strengths of each medium correctly is the secret to effective blended learning. It integrates the two separate learning environments such that each medium complements the other in an integrated way. One of the main aspects is how it can be applied to help students improve their academic objectives and achieve them.

Recommendations on blended course design are provided to increase the empowerment of learners. It may create a dilemma for any institution which has physical infrastructure. Changing it takes time. Consequently, it is necessary to think about what it means to strain the blended learning approach when the physical infrastructure is not ready yet. Moreover, more research has to be done to identify and deal with challenges faced in this intelligent era.

\section{REFERENCES}

Bandura, A. (1977). Self-Efficacy: Toward a Unifying Theory of Behavioral Change. Psychological Review, 84(2), 191.

Cotfas, D. T., Cotfas, P. A., \& Kaplanis, S. (2013). Methods to Determine the DC Parameters of Solar Cells: A Critical Review. Renewable and Sustainable Energy Reviews, 28, 588-596.

Effoduh, J. O. (2016). The Fourth Industrial Revolution by Klaus Schwab.

Fahlvik, M. (2014). The Teacher's Role in the Blended Classroom. In Practical Applications and Experiences in K-20 Blended Learning Environments (pp. 239-248). IGI Global.

Lynch, R., \& Dembo, M. (2004). The Relationship between Self-regulation and Online Learning in a Blended Learning Context. The International Review of Research in Open and Distributed Learning, 5(2).

Maddux, J. E. (2016). Self-efficacy. In Interpersonal and intrapersonal expectancies (pp. 41-46). Routledge. 
BL'TALL (ENGLISH LANGUAGE 'TEACHING, APPIIEI) LINGUISTICS

AND II'TIRA'TURI)

Vol. 2 No. 1, 2021

Available online at https:/ /jurnal.iainponorogo.ac.id/index.php/eltall

Maxwell, C. (2016). What Blended Learning Is-and Isn't. BLU: Blended Learning Universe.

Nguyen, T. T. (2010). Knowledge Acquisition in a Hybrid Graduate Teacher Training Program. In Handbook of Research on Hybrid Learning Models: Advanced Tools, Technologies, and Applications (pp. 317-326). IGI Global.

Olah, D. A. (2019). Technology Tools for Integration in the Classroom. In Faculty Roles and Changing Expectations in the New Age (pp. 101-114). IGI Global.

Owston, R. (2018). Empowering Learners through Blended Learning. International Journal on E-Learning, 17(1), 65-83.

Rubin, R. B., Martin, M. M., Bruning, S. S., \& Powers, D. E. (1993). Test of a Selfefficacy Model of Interpersonal Communication Competence. Communication Quarterly, 41(2), 210-220.

Shahroom, A., \& Hussin, N. (2018). Industrial Revolution 4.0 and Education. International Journal of Academic Research in Business and Social Sciences, $8(9), 314-319$.

Shea, P., \& Bidjerano, T. (2010). Learning Presence: Towards a Theory of SelfEfficacy, Self-Regulation, and the Development of a Communities of Inquiry in Online and Blended Learning Environments. Computers \& Education, 55(4), 1721-1731.

Strauss, A., \& Corbin, J. (1990). Basics of Qualitative Research. Sage publications.

Thomas, K. W., \& Velthouse, B. A. (1990). Cognitive Elements of Empowerment: An "Interpretive" Model of Intrinsic Task Motivation. Academy of Management Review, 15(4), 666-681.

Tomlinson, B., \& Whittaker, C. (2013). Blended Learning in English Language Teaching. London: British Council. 